\section{Unjustified killing of badgers in Kyushu}

An ecological crisis is unfolding on Kyushu Island, Japan. Thousands of Japanese badgers (Meles anakuma) are being culled illegally without scientific advice or strategic planning. We urge the government to intervene and work with ecologists to establish whether this increase in culling is warranted. Justified culls should then be planned, regulated, monitored for effectiveness and subjected to animal-welfare controls (see Nature 543, 18-19; 2017).

Badgers are protected under Japanese law. Typically, some 200 are legally culled every year in Kyushu's Kagoshima prefecture to prevent crop destruction. But, inexplicably, local farmers killed 4,000 badgers last year. And because the Japanese name for badger - anaguma - is a generic term for all face-masked mesocarnivores, species such as raccoon dogs (Nyctereutes procyonoides viverrinus) and raccoons (Procyon lotor) are also being exterminated.

To encourage farmers to deal with problem animals, the local authorities offer the equivalent of US $\$ 25$ for each badger tail or each carcass photographed. Locals therefore stand to profit from the culling. Another factor could be the trend for exotic bush meat in exclusive Tokyo restaurants.

In our view, formal regulation of this culling is essential. Proper meat controls are also needed to prevent food poisoning and the spread of parasitic infections to humans.

Yayoi Kaneko Tokyo University of Agriculture and Technology, Japan. Christina D. Buesching, Chris Newman University of Oxford, UK. ykaneko@cc.tuat.ac.jp

\section{Outsmart supply dips in renewable energy}

Integrating intermittent renewable-energy supplies into existing electricity grids in a stable way will depend on artificial intelligence. Such a system could process massive volumes of consumption data and adjust power usage almost instantly, giving real-time control over supply and demand.

Domestic consumers would be rewarded (with cheaper bills) for shifting their energy demand at short notice when the grid has a power imbalance, as is already the case for large industrial consumers and gridscale storage systems. Smart meters that collect household consumption data would enable this process. By 2020, the United Kingdom aims to have such meters in 26 million homes and the European Union has a target of 200 million.

These meters would contain microcontroller devices that communicate wirelessly with the grid. The meter could then momentarily dim lighting or switch off electric heaters, for example, without discomforting the occupiers.

The efficiency of this process will depend on demand predictions for individual consumers, which involves using large amounts of data to model people's energy constraints and preferences over time. Embedded artificial intelligence will analyse and model these consumption data, enabling the grid response to occur within seconds.

Valentin Robu, David Flynn

Heriot-Watt University,

Edinburgh, UK.

v.robu@hw.ac.uk

\section{Plug gap in essential bioinformatics skills}

Life scientists urgently need early training in bioinformatics skills. That is the finding of surveys by the Global Organisation for Bioinformatics Learning, Education and Training (GOBLET; http:// mygoblet.org). Bioinformatics is now intrinsic to life-sciences research, but the skills necessary for basic data stewardship are still taught in only some $25 \%$ of education programmes, creating an unacceptable chasm between theory and practice.

Almost 500 researchers worldwide, ranging from graduate students to career scientists, responded to the 2014 GOBLET survey on the extent of their bioinformatics training (see M. D. Brazas et al. Preprint at bioRxiv http:// dx.doi.org/10.1101/098996; 2017). The results revealed a high demand for short courses that could improve researchers' expertise in data analysis and interpretation, ideally delivered before they embark on designing experiments and collecting data.

Universities must invest in degree-level education in bioinformatics, to ensure that wet-lab teams comprise computationally minded biologists who can take on programming and the statistical components of data analyses.

Meanwhile, the GOBLET foundation is working to enlarge the international community of bioinformatics trainers and training resources, to help prevent research progress being impeded as a result of gaps in researchers' bioinformatics skills (see J. Chang Nature 520, 151-152; 2015).

Michelle D. Brazas Ontario Institute for Cancer Research, Toronto, Canada.

Sarah Blackford University of Lancaster, UK.

Teresa K. Attwood University of Manchester, UK.

michelle.brazas@oicr.on.ca

\section{Reforms overdue for ethical reviewing}

The US government is seeking to exempt low-risk research involving human participants from ethical review. We consider this reform to be long overdue, and not just in the United States.

In our view, the lengthy and costly process of ethical review is overprotective in low-risk studies such as surveys, aptitude

testing and ordinary psychology experiments, and could undermine scientific progress. The cost of ethical clearance for an Australian study of a lowrisk public-health intervention, for example, was estimated at Aus $\$ 25,000$ (US\$19,000) (A. G. Barnett et al. Res. Integr. Peer Rev. 1, 16; 2016).

This overprotection stems partly from the skewed incentives for reviewing committees, hired by institutions to design and implement protection policies. These custodians are held accountable for failure but not rewarded for success, which encourages overly conservative and lengthy ethics-clearance procedures.

Changes to protective rules are unlikely when the possible risks loom larger than the cost savings. This is because of the disproportionate weighting of rare extreme events - for instance, a risk increase of $0 \%$ to $1 \%$ may be seen as more alarming than one from $40 \%$ to $41 \%$. Institutions may therefore opt to play safe, despite the low probability of such events.

These factors cause the costs of protective regulations to outweigh the benefits in lowrisk studies. We should accept that zero-risk research is an impossible goal that cannot justify the diversion of scarce public resources from improving collective knowledge and benefiting society. As such, the costs of overprotection raise ethical concerns of their own. Lionel Page, Katie Page Queensland University of Technology, Brisbane, Australia. lionel.page@qut.edu.au

CONTRIBUTIONS

Correspondence may be submitted to correspondence@nature. com after consulting the author guidelines at http://go.nature.com/ cmchno. 